\title{
Proje aşamasında öngörülen ve mevcut durumda sağlanan verimin karşılaştırılması: Azerbaycan Nahçıvan atıksu arıtma tesisi örneği
}

\section{The comparison of efficiency between project phase and current situation-case study of Azerbaijan Nakhchivan wastewater treatment plant}

\author{
Ahmet Saatçı ${ }^{1}$ * (iD), Özge Hanay² \\ ${ }^{1}$ Bingöl Üniversitesi, SHMYO, Çevre Să̆lı̆̆ Programı. 12000, Bingöl, Türkiye \\ ${ }^{2}$ Firat Üniversitesi, Çevre Mühendisliği Bölümü, 23100, Elazığ, Türkiye
}

\begin{abstract}
Özet
Günümüzde artan nüfus ile atıksu miktarı ve kirletici konsantrasyonları da nüfusa paralel olarak artmaktadır. Atıksuların olumsuz etkilerini en aza indirmeyi amaçlayan arıtma tesislerinde karşılaşılan problemler araştırıldığında, sorunların bazen proje aşamasındaki hatalardan, bazen de işletme hatalarından kaynaklandığı görülmektedir. $\mathrm{Bu}$ hatalar beklenenin üzerinde işletme maliyetlerini beraberinde getirmektedir. $\mathrm{Bu}$ nedenle proje aşaması ve işletme aşamasında dikkat edilmesi gereken noktaların belirlenmesi ve geliştirilmesi önemli bir konu haline gelmiştir. $\mathrm{Bu}$ çalışma kapsamında $\mathrm{A}^{2} \mathrm{O}$ prosesi olarak tasarlanarak 2018 yılında işletmeye alınan Azerbaycan Nahçıvan Atıksu Arıtma Tesisinin proje aşamasında ve işletme aşamasındaki hedeflenen kirlilik giderim verimi kıyaslanmıştır. Tesisin 12 ay boyunca BO ${ }_{5}$, KOİ, AKM, $\mathrm{TN}$ ve TP parametreleri incelenmiştir. Tesise gelen ortalama $\mathrm{BOI}_{5}$ ve KOİ konsantrasyonunun 1. kademe proje hesaplarından yaklaşık \%33 düşük olduğu gözlemlenmiştir. Kirlilik yüklerinin yüksek hesaplanması sonucu C:N:P oranı değişmiş, karbon kaynağı eksikliğinden kaynaklı çeşitli işletme problemleri ve verim kaybı oluşmuştur. Bu örnek tesis üzerinden projelendirme aşamasında yerinde ölçümler yapılmasının ve güncel hesap metotları kullanılmasının önemi vurgulanmıştır.
\end{abstract}

Anahtar kelimeler: Arıtma verimi, Tasarım kriterleri, Atıksu aritma tesisi, Azerbaycan

\section{Giriș}

Dünyamızdaki hızlı nüfus artışı ve teknolojik gelişmeler ile ekolojik sistemin en önemli parçası olan su kaynakları hızla kirlenmekte ve oluşan atıksu miktarları artmaktadır [1]. Dünyada her on kişiden ikisinin güvenli içme suyuna erişimi bulunmamakta ve kuraklık nedeniyle pek çok ülkede su kısıtlamaları yaşanmaktadır. Bu nedenle kullanılmış suların arıtım sürecinden geçerek aynı sisteme geri döndürülmek ya da başka bir amaç için kullanılmak üzere yeniden kullanımı ve su tasarrufu için azami gayret gösterilmesi giderek daha fazla önem kazanmaktadır [2].

\begin{abstract}
Today, with the increasing population, the amount of wastewater and concentrations of pollutants are increasing in parallel with the population. When investigating problems at treatment plants aimed at minimizing the negative impact of wastewater, it is observed that problems are sometimes caused by mistakes at the project stage and sometimes by operating errors. These errors lead to higher operating costs than expected. Therefore, the determination and development of points to be considered both during the project and operation phase has become an important issue. In this study, the efficiency of pollution removal targeted at the project stage and the efficiency of pollution removal at the operating stage of the Azerbaijan Nakhchivan Wastewater Treatment Plant, which was designed as an $\mathrm{A}^{2} \mathrm{O}$ process and started to operate in 2018 , were compared. The wastewater treatment plant parameters of $\mathrm{BOD}_{5}, \mathrm{COD}$, MLSS, TN and TP were examined for 12 months. When these parameters were analyzed, it was observed that the average concentration of $\mathrm{BOD}_{5}$ and $\mathrm{COD}$ arriving at the WWTP was approximately 33\% lower than the 1 stage project calculations. As a result of high calculation of pollution loads, the $\mathrm{C}: \mathrm{N}: \mathrm{P}$ ratio changed, various operating problems and loss of efficiency occurred due to carbon deficiency. The importance of using on-site measurements and ideal calculation methods at the project design stage was emphasized through this WWTP.
\end{abstract}

Keywords: Treatment efficiency, Design criteria, Wastewater treatment plant, Azerbaijan

Atıksu arıtma tesisleri (AAT) gerek yatırım maliyeti, gerekse işletme maliyeti yüksek tesislerdir. Yüksek maliyetli bu tesislerin tasarım aşamasında analizler titizlikle yapılmalı ve tesis devreye alındığında doğru işletme ile hedeflenen çıkış suyu kalitesine ulaşılmalıdır. Tesisin yapılacağı yerleşim biriminin atık suyunun içerdiği kirleticilerin dikkatli bir şekilde tespit edilmesi, tesis yatırım ve işletme maliyetini mümkün olduğunca düşürecek ve işletme kolaylığı sağlayacaktır. Doğru prosesin seçilmesi için gelecek nüfus, debi ve kirlilik yüklerinin yüksek doğrulukla hesaplanması ve tesis performansını belirleyecek tüm faktörlerin proje aşamasında dikkatlice değerlendirilmesi

\footnotetext{
* Sorumlu yazar / Corresponding author, e-posta / e-mail: asaatci@ bingol.edu.tr (A. Saatçi)

Geliș / Recieved: 06.03.2020 Kabul / Accepted: 16.07.2021 Yayımlanma/ Published: 14.01.2022

doi: 10.28948/ngmuh.699574
} 
gerekir. $\mathrm{Bu}$ değerlendirmelerin uygun bir şekilde yapılmaması arıtma tesislerinin işletmesini yapan kuruluşlarda sorunlara neden olmaktadır. $\mathrm{Bu}$ sorunlar tesislerin ilk kuruluş ve işletme maliyetlerine büyük yük getirmektedir. Arıtma tesislerinin öngörülen verimi sağlaması ne derece rasyonel olarak projelendirildiği ile alakalıdır. Atıksu arıtma tesislerinin projelendirilmesi ve işletilmesi ile ilgili çok sayıda çalışma mevcuttur.

Amerika Çevre Koruma Ajansı (EPA) [3] yayınladığı bildiride herhangi bir atıksu akışının etkin yönetimi için özellikleri hakkında makul derecede doğru bir bilgi gerektiğini belirtmiştir. $\mathrm{Bu}$ atıksularla ilgili ayrıntılı karakterizasyon verilerinin yalnızca atıksu arıtma ve bertaraf sistemlerinin etkili tasarımını kolaylaştırmak için değil, aynı zamanda su koruma ve atık yükü azaltma stratejilerinin geliştirilmesini ve uygulanmasını sağlamak için de gerekli olduğunu vurgulamıştır.

Reynolds ve Richards [4] aritma tesislerinin uygun şekilde çalışmasını sağlamak için bakılması gereken parametreler ve testleri incelemişlerdir. Yine aynı çalışmada aktif çamur süreçlerinde karşılaşılan işletme problemlerini ele almıştır.

Qasim [5] bir su kirliliği problemini belirlemek, tasarım verilerini geliştirmek, alternatifleri değerlendirmek ve bir çözüm önermek için bir tesis planı hazırlanmıştır. Tesis planında geliştirilen veriler, atıksu arıtma tesislerinin tasarım planlarının, şartnamelerinin ve maliyet tahminlerinin hazırlanmasında kullanılmaktadır.

Değirmenci vd. [6] tarafindan yapılan çalışmada atıksu miktarı ve $\mathrm{BOİ}_{5}$ kirlilik yükünün, havalandırma havuzu ilk yatırım ve enerji maliyetlerine olan etkileri incelenmiş, yapılan çalışmalar sonucunda; $\mathrm{BOI}_{5}$, debi, F/M ve UAKM miktarındaki değişimlerin ilk yatırım ve enerji maliyetlerini önemli ölçülerde değiştirdiği belirlenmiştir.

Tchnobanoglous vd. [7] arıtma tesisi tasarım süreçlerinin önemini belirtmiş, tesis tasarım ve hesaplamalarını açıklayan bir çalışma gerçekleştirmiştir.

Alpaslan vd. [8] tarafindan hazırlanan "Atıksu Arıtma Tesislerinin Tasarım ve Proje Kontrol Esasları" isimli çalışmada atıksu arıtma tesisleri tasarımında dikkat edilecek parametreler hakkında bilgi verilmiş ve atıksu arıtma tesislerinde kullanılan ekipmanların çalışma prensipleri, kullanım şartları, tesis prosesleri açıklanmıștır.

Topal vd. [9] Elazığ Belediyesi Atıksu Arıtma Tesisi’nin 2010-2011 kış sezonunda mevcut durumu değerlendirilmiş ve tesisin $\mathrm{pH}$, sicaklık, debi, Çözünmüş Oksijen (ÇO), Askıda Katı Madde (AKM) ve Kimyasal Oksijen İhtiyacı (KOİ) parametrelerinin değişimini incelenmişlerdir.

Tatar ve Sağlam [10] Kızıltepe İleri Biyolojik arıtma tesisinin 24 saatlik kompozit numuneler ile KOİ, $\mathrm{BOI}_{5}$ ve AKM parametrelerini analiz edip giderim verimliliğini gözlemlemişlerdir.

$\mathrm{Bu}$ çalışmanın amacı yapılması planlanan evsel atıksu arıtma tesislerinin tasarım parametrelerinde yaşanabilecek hataları bir tesis üzerinden ele almak ve karşılaştırmalı değerlendirme ile sonuçlarını tartışarak projelendirme aşamasında nüfus tahmin metotlarında doğruluk payı yüksek hesaplamaların kullanılmasının, debi, kirlilik yükü gibi parametrelerinin yerinde ölçümünün yapılmasının önemini vurgulayarak literatüre katkı sağlamaktır. Bu amaçla Azerbaycan Nahçıvan AAT örneği üzerinden bir çalışma gerçekleştirilerek, proje aşamasında hedeflenen verim ve işletme parametreleri ile yapım sonrası işletme verimi kıyaslanarak projenin ne derece isabetli ve rasyonel olduğu değerlendirilmiş, tasarım aşamasında hassas olarak yapılması gereken hesaplamalara dikkat çekilmiştir.

\section{Materyal ve metot}

Yerel yönetimler halkın ihtiyaçlarını karşılamak ve çevre koruma politikaları gereğince atıksuları arıtarak alıcı ortama deşarjını sağlamakla yükümlüdür. Bu çerçevede, atıksuların deşarj edildiği ortama olumsuz etkilerini en aza indirmeyi amaçlayan Azerbaycan Nahçıvan AAT 2010 yılında projelendirilmiş ve 2018 yilında tamamlanarak işletmeye alınmıştır. Azerbaycan Nahçıvan AAT'nde, ileri biyolojik arıtma sistemi olan $\mathrm{A}^{2} \mathrm{O}$ (anaerobik/anoksik/aerobik) prosesi seçilmiştir. $\mathrm{Bu}$ sistem, atıksuyun deşarj limitlerini sağlamak ve alıcı ortamı korumak amacıyla eş zamanlı karbon, azot ve fosfor giderimini hedeflemektedir. Çalışmada tesisin tasarım kriterleri ele alınarak sonuçlar ile karşılaştırma yapılmıştır.

\subsection{Nahçıvan atıksu arıtma tesisi tasarım kriterleri}

Nahçıvan AAT, Nahçıvan şehir merkezi ve çevresindeki 5 beldeye hizmet vereceği için nüfus projeksiyonu belirlenirken, Nahçıvan şehri ve çevresindeki 5 beldenin nüfusları toplanarak hesaplamalar yapılmıştır. Nahçıvan AAT için nüfus projeksiyon analizi Tablo 1'de özetlenmiş̧ir.

Tablo 1. Nahçıvan nüfus projeksiyonu

\begin{tabular}{ccc}
\hline Hesap Yöntemi & $\begin{array}{c}2022 \text { Yılı } \\
\text { Nüfusu (kişi) }\end{array}$ & $\begin{array}{c}\text { 2034 Yılı Nüfusu } \\
\text { (kişi) }\end{array}$ \\
\hline En Küçük Kareler Yöntemi & 100514 & 116739 \\
Aritmetik Artış Metodu & 102523 & 120860 \\
Üssel Yöntem & 92548 & 101740 \\
*Öngörülen Artı̧ (\%2) & 106768 & 135408
\end{tabular}

*Azerbaycan Resmi İstatistik Kurumu tarafından öngörülen nüfus artış hizı

Tablo 1'de görüldüğü gibi farklı yöntemlerle hesaplanan nüfus tahminlerinde Azerbaycan Nahçıvan nüfusunun 2022 yılı için 92548 - 106768 kişi; 2034 yllı için 101740 - 135408 kişi olarak değişen değerler elde edilmektedir. Burada Azerbaycan resmi istatistik kurumu "Azərbaycan Respublikasının Dövlət Statistika Komitəsi" nin belirlediği nüfus artış hızı esas alınarak bulunan;

$\mathrm{N}_{2022}=106768$ kişi, $\mathrm{N}_{2034}=135408$ kişi nüfus değerleri hesaplara esas alınmıştır.

\subsubsection{Debi hesaplarl}

Nahçıvan AAT proje kabullerinde evsel debiler için günlük kişi başı su tüketimi şebeke sayaçlarından 30 günlük verilerin ortalaması alınarak $167 \mathrm{~L} /$ kişi-gün kabul edilmiştir. $\mathrm{Su}$ tüketiminin \%90'ının kanalizasyon şebekesine intikal edeceği kabul edilmiştir. Yağmur suyu debisi olarak evsel atıksu debisinin \% 10 'u maksimum debi hesaplarında dikkate alınmıştır. Tablo 2'de Nahçıvan AAT debi miktarları proje müellifi tarafindan hesaplanarak yıllara göre verilmiştir. 
Tablo 2. Nahçıvan AAT debi hesabı

\begin{tabular}{|c|c|c|c|}
\hline Debi Hesabı & 2011 & 2022 & 2034 \\
\hline${ }^{1}$ Nüfus & 85870 & 106768 & 135408 \\
\hline${ }^{2}$ Evsel Su İhtiyacı (L/sn) & 165.98 & 206.37 & 261.73 \\
\hline 33urumların İhtiyacı (L/sn) & 8.30 & 10.32 & 13.09 \\
\hline${ }^{4}$ Ticari İhtiyaç (L/sn) & 16.60 & 20.64 & 26.17 \\
\hline${ }^{4}$ Endüstri İhtiyacı (L/sn) & 16.60 & 20.64 & 26.17 \\
\hline $\begin{array}{l}\text { Toplam Yerleşim Dişı } \\
\text { İhtiyaç (L/sn) }\end{array}$ & 41.49 & 51.59 & 65.43 \\
\hline Toplam Alıcı İhtiyacı (L/sn) & 207.47 & 257.96 & 327.16 \\
\hline${ }^{5}$ Sizıntı (L/sn) & 20.75 & 25.80 & 32.72 \\
\hline${ }^{6}$ Kayıр (L/sn) & 10.37 & 12.90 & 16.36 \\
\hline TOPLAM (L/sn) & 238.59 & 296.66 & 376.23 \\
\hline TOPLAM (m³/gün) & 20614.1 & 25631.0 & 32506.4 \\
\hline 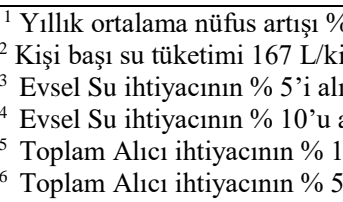 & $\begin{array}{l}\text { abul ediln } \\
\text { ün olarak } \\
\text { ş̧ır. } \\
\text { nıştır. } \\
\text { alınmıştır. } \\
\text { Inmışır. }\end{array}$ & ıştır. & \\
\hline
\end{tabular}

Atıksu arıtma tesisi tasarımı için proje müellifi tarafından hesaplanan tasarım debisi, ortalama debi, minimum ve maksimum debiler Tablo 3 'te gösterilmiştir.

Tablo 3. Nahçıvan AAT kabul edilen debiler

\begin{tabular}{cccc}
\hline Tasarım Debileri (m³/gün) & \multicolumn{3}{c}{ Ylllar } \\
& 2011 & 2022 & 2034 \\
\hline $\mathrm{Q}_{\text {tasarmm }}$ & 38730 & 43293 & 53337 \\
$\mathrm{Q}_{24 \text { ort }}$ & 20614 & 25631 & 32506 \\
$\mathrm{Q}_{\min }$ & 14221 & 16529 & 19051 \\
$\mathrm{Q}_{\max }$ & 42417 & 51317 & 65513 \\
\hline
\end{tabular}

\subsubsection{Kirlilik yükü hesaplarl}

Proje müellifi tarafından kirlilik yükü hesaplamalarında 2011 ve 2022 yılı BOİ 5 konsantrasyonu 60 g/kişi-gün, 2034 y1lı için $\mathrm{BOİ}_{5}$ konsantrasyonu $65 \mathrm{~g} /$ kişi-gün alınmıştır. AKM, toplam azot (TN) ve toplam fosfor (TP) yükleri de 2011 ve 2022 yılları için aynı alınmış olup AKM: 70 g/kişigün, TN: 10 g/kişi-gün ve TP: 3 g/kişi-gün olarak alınmıştır. Şehirde yer alan mezbaha kaynaklı atıksular için literatürde verilen kirlilik konsantrasyonları kullanılmıştır $\left(\mathrm{BOI}_{5}=2500\right.$ $\mathrm{mg} / \mathrm{L}, \mathrm{AKM}=1000 \mathrm{mg} / \mathrm{L}, \mathrm{TKN}=300 \mathrm{mg} / \mathrm{L}, \mathrm{P}=6.5 \mathrm{mg} / \mathrm{L}$ ). Projelendirme geri devir oran $\mathrm{R}=1.1$ ve işletmeye esas $\mathrm{F} / \mathrm{M}=0.3$ olarak alınmıştır. Kabul edilen kirlilik yükleri Tablo 4'te ayrı ayrı gösterilmiştir.

Tesisin arıtım verimi 91/271/EEC No'lu Avrupa Birliği Kentsel Atıksu Arıtımı Direktifine göre verilmiş olan KOİ, BOI, AKM, TN ve TP değerlerinin alıcı ortama deşarj standartları esas alınarak değerlendirilmiştir. Tesis performansı ve kirletici parametreleri bu yönetmelik ve proje raporundaki hedefler kıyaslanarak yapılmıştır. Tablo 5'de AB Kentsel Atıksu Arıtımı direktifinde belirlenen deşarj limitleri gösterilmektedir.
Tablo 4. Nahçıvan AAT hesaplamalarında kabul edilen birim kirlilik yükleri (g/kişi-gün)

\begin{tabular}{cccc}
\hline Evsel Atıksu Karakterizasyonu & 2011 & 2022 & 2034 \\
\hline BOİ $_{5}$ (g/kişi-gün) & 60 & 60 & 65 \\
KOİ (g/kişi-gün) & 100 & 100 & 110 \\
AKM (g/kişi-gün) & 70 & 70 & 70 \\
TN (g/kişi-gün) & 10 & 10 & 11 \\
TP (g/kişi-gün) & 3 & 3 & 3 \\
\hline
\end{tabular}

Tablo 5. 91/271/EEC No'lu AB Direktifine göre kentsel atıksu deşarj limitleri

\begin{tabular}{ccc}
\hline PARAMETRE & $\begin{array}{c}\text { *Deşarj Limitleri } \\
(\mathrm{mg} / \mathrm{L})\end{array}$ & $\begin{array}{c}\text { Min. Arıtma Verimi } \\
(\%)\end{array}$ \\
\hline BOİ $_{5}$ & 25 & $70-90$ \\
KOİ & 125 & 75 \\
$\mathrm{AKM}$ & 35 & 90 (Nüfus $>10000)$ \\
$\mathrm{TN}$ & 15 & 80 \\
$\mathrm{TP}$ & 2 & $70-80$ \\
\hline
\end{tabular}

Proje müellifi tarafindan hazırlanan 1. kademe yılı kirlilik yükleri ve 2 . kademe yılı kirlilik konsantrasyonları ve hedeflenen arıtma verimleri Denklem (1) ve (2)'ye göre hesaplanarak Tablo 6'da gösterilmiştir. Tesisin deşarj limitleri 91/271/EEC No'lu Avrupa Birliği Kentsel Atıksu Arıtımı Direktifine göre kabul edilmiştir.

$$
\begin{gathered}
\text { Kirlilik Yükü }\left(\frac{k g}{g u ̈ n}\right)=\frac{\operatorname{Birim} y \ddot{u} k\left(\frac{g r}{k i s ̧ i . g u ̈ n}\right) \times \text { Mevcut nüfus (kişi) }}{1000} \\
\text { Konsantrasyon }\left(\frac{m g}{L}\right)=\frac{\text { Kirlilik yü } k \ddot{u}\left(\frac{k g}{g \ddot{u} n}\right)}{\operatorname{Debi}\left(\frac{m^{3}}{g \ddot{u} n}\right)}
\end{gathered}
$$

Tablo 6. Proje kademelerine göre kirlilik konsantrasyonları

\begin{tabular}{|c|c|c|c|c|c|}
\hline \multirow[b]{2}{*}{ 崩 } & \multirow{2}{*}{ 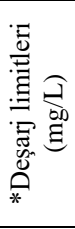 } & \multicolumn{2}{|c|}{$\begin{array}{l}\text { 1.Kademe nüfuslarına } \\
\text { göre }\end{array}$} & \multicolumn{2}{|c|}{$\begin{array}{l}\text { 2.Kademe nüfuslarına } \\
\text { göre }\end{array}$} \\
\hline & & $\begin{array}{c}\text { Hesaplanan } \\
\text { kirlilik } \\
\text { kons. } \\
(\mathrm{mg} / \mathrm{L})\end{array}$ & $\begin{array}{c}\text { Hedef } \\
\text { min. } \\
\text { aritma } \\
\text { verimi } \\
(\%) \\
\end{array}$ & $\begin{array}{l}\text { Hesaplanan } \\
\text { kirlilik kons. } \\
\quad(\mathrm{mg} / \mathrm{L})\end{array}$ & $\begin{array}{c}\text { Hedef } \\
\text { min. } \\
\text { aritma } \\
\text { verimi } \\
(\%) \\
\end{array}$ \\
\hline $\mathrm{BOI}_{5}$ & 25 & 201. & 87.56 & 270.76 & 90.76 \\
\hline KOİ & 125 & 335.02 & 62.69 & 458.21 & 72.72 \\
\hline AKM & 35 & 234.52 & 85.08 & 291.59 & 87.99 \\
\hline TN & 15 & 33.50 & 55.22 & 45.82 & 67.26 \\
\hline TP & 2 & 10.05 & 80.10 & 12.50 & 83.99 \\
\hline
\end{tabular}
$(\mathrm{mg} / \mathrm{L})$ ve minimum arıtma verimleri

\subsubsection{Nahçıvan atıksu arıtma tesisi proses seçimi}

Nahçıvan Su Temini Komitesi tarafından AAT çıkış suyunun tarımsal sulama amaçlı kullanımı düşünülmektedir. Sulama suyu olarak kullanılacak sulara ileri arıtım (karbon, azot ve fosfor giderimi) uygulanması gerekmektedir [7]. Tasarım hesaplarının değerlendirilmesi sonucunda tesisin BOİ/P oranının 20 olduğu kabul edilerek, eş zamanlı 
nitrifikasyon-denitrifikasyon ve fosfor giderimine olanak sağlayan $\mathrm{A}^{2} \mathrm{O}$ prosesi uygulanabileceği belirlenerek tesiste son çöktürme tank1 yerine membran entegreli $\mathrm{A}^{2} \mathrm{O}$ prosesi tercih edilmiştir.

Arıtma tesisini oluşturan üniteler; otomatik temizlemeli kaba ve ince 1zgaralar, havalandırmalı kum ve yağ tutucu, döner tambur elek, dengeleme havuzu, anaerobik havuzlar (biyofosfor havuzu), anoksik havuzlar, aerobik aktif çamur havuzları, membran reaktörler, geri devir merkezi, çamur yoğunlaştırma ve çamur susuzlaştırma ünitesidir. Tesis akım şeması Şekil 1'de gösterilmiştir.

Tesiste sirasıyla sisteme gelen atıksular kaba ve ince 1zgara ünitelerine iletilir. Kaba 1zgarada $40 \mathrm{~mm}$ 'den iri maddelerden, ince 1zgarada $5 \mathrm{~mm}$ 'den büyük çaplı katı maddelerden arındırılan atıksu daha sonra döner tambur eleğe gelir. Burada 0.3 mm'den büyük çaplı katı maddeler tutulur. Ardından atıksu kum tutucu ünitelerine, aktarılır ve burada atıksu içinde bulunan ve mekanik ekipmanlara zarar vermesi muhtemel olan kumlardan ve yağdan arındırılarak pompalar vasitasiyla dengeleme havuzuna gönderilir. Dengeleme ünitesinden çıkan atıksular biyolojik arıtıma başlar ve fosfor arıtımının da öngörüldüğü tesislerde anaerobik ve anoksik havuzlara oradan da aerobik şartların sağlanacağı havalandırma havuzlarına gönderilir. Havalandırma havuzlarında karbonlu organik madde ve fosfor gideriminin sağlanmasının ardından atıksuda askıda bulunan mikroorganizmalar harici membranlar aracılığıyla atıksudan ayrıştırılarak arıtılmış atıksu sulamada kullanılmak üzere sulama havuzuna deşarj edilir. Arıtılan atıksular tarımsal sulamada kullanılacak ise dezenfeksiyona veya diğer ileri arıtma yöntemlerine tabi tutulması gerekmektedir. Dezenfeksiyon amaciyla tesiste ozonlama işlemi tercih edilmiştir. Membranlarda tutulan mikroorganizmalar çamur susuzlaştırma ünitelerinden geçirilerek katı hale dönüştürülür ve uygun bertaraf yöntemleri ile bertaraf edilir.

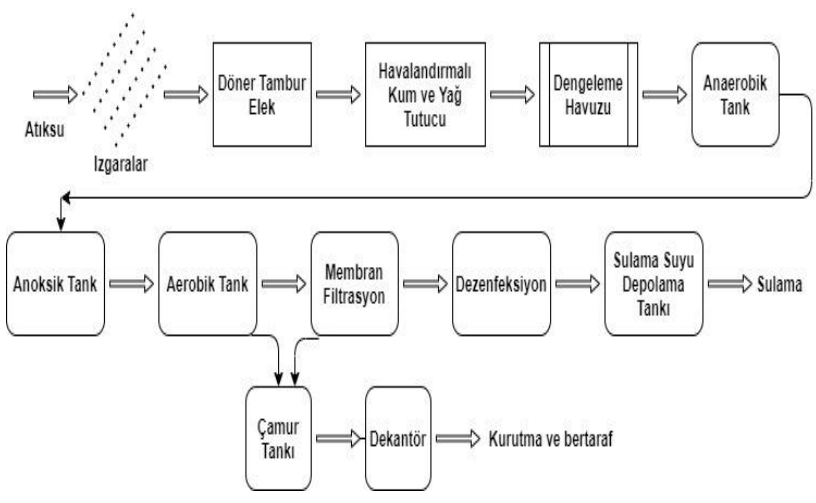

Şekil 1. Nahçıvan AAT proses akım şeması

\subsubsection{Analiz metotlarl}

Atıksuya ait kirlilik parametrelerinin analizi arıtma tesisine ait laboratuvarda yapılmıştır. TS ISO 5667-10 standardına göre numuneler alınmıştır. TS EN ISO 5667-3 standardına göre numuneler korunmuştur. $\mathrm{BOI}_{5}$ analizi SM 5210 B standardına göre, KOİ analizi TS 2789 standardına göre ve AKM analizi TS EN 872 standardına göre, TN analizi TS EN 12260 standardına göre ve TP analizi SM 4500 PB standardına göre yapılmıştır.

\section{Bulgular ve tartışma}

Nahçıvan AAT Kasım 2017'de işletmeye alınmıştır. Bu çalışmada; Ocak 2018 - Aralık 2018 tarihleri arasında tesis girişi ve çıkışından alınan 2 saatlik kompozit numunelerin laboratuvar analiz sonuçlarına göre değerlendirmeler yapılmıştır.

\section{1. $B O \dot{I}_{5}, K O I$ ve AKM giderim verimlerinin klyaslanmasl}

Aritma tesisinin hedeflenen aritma verimini sağlayabilmesi için sistemin otomasyonunun sağlanması ve işletme parametrelerinin düzenli bir şekilde izlenerek rutin olarak analizlerin yapılması gerekmektedir [9]. Şekil 2'de verilen grafikte 2018 yilının Ocak-Aralık periyodunda Nahçıvan AAT'nin giriş ve çıkışından alınan 2 saatlik kompozit numunelerin $\mathrm{BOI}_{5}$ konsantrasyonlarının değişimi ve deşarj standardı olarak kabul edilen Avrupa Birliği Kentsel Atıksu Arıtımı Direktifinde belirtilen BOİ ${ }_{5}$ deşarj limiti gösterilmektedir. Çıkış numunesinin $\mathrm{BOI}_{5}$ konsantrasyonlarının 12 ay süresince yönetmelik deşarj sınırı olan $25 \mathrm{mg} / \mathrm{L}$ 'den düşük olduğu görülmektedir. En fazla kirlilik konsantrasyonunun olduğu ay Mart 2018'de $165.2 \mathrm{mg} / \mathrm{L}$, en düşük olduğu ay ise Temmuz 2018'de 100.2 $\mathrm{mg} / \mathrm{L}$ olarak ölçülmüştür. Analiz süresince ortalama giriş $\mathrm{BOI}_{5}$ konsantrasyonu $133.23 \mathrm{mg} / \mathrm{L}$, çıkış konsantrasyonu $7.78 \mathrm{mg} / \mathrm{L}$ 'dir. Sonuçların kabul edilen yönetmelikte belirlenen $\mathrm{BOI}_{5}$ deşarj limitlerine uygun olduğu görülmektedir.

Toplam giriş BOİ konsantrasyonlarına bakıldığında, 12 ay süresince tesise gelen ortalama $\mathrm{BOI}_{5}$ konsantrasyonu, tesisin projelendirme hesaplarında 1 . kademe $\mathrm{BOI}_{5}$ kirlilik konsantrasyonu olan $201.01 \mathrm{mg} / \mathrm{L}$ 'ye kıyasla yaklaşık \%33 daha düşük olduğu gözlemlenmiştir. Aynı grafikte BOİ giderim verimindeki değişim ve proje aşamasında hedeflenen verim de gösterilmektedir.

Proje aşamasında 1 . kademe için $\mathrm{BOI}_{5}$ giderim verimi hedefi \% 87.56'dır. Arıtma verimleri analiz edildiğinde $\mathrm{BOI}_{5}$ arıtma veriminin yıl boyunca yönetmelikte kabul edilen sınır değerlerin üstünde olduğu görülmektedir. Yıllık ortalama $\mathrm{BOI}_{5}$ arıtma verimi \% 94.25 olarak hesaplanmıştır ve proje aşamasında hedeflenen 1. kademe arıtma veriminin üzerinde olduğu gözlemlenmektedir.

Şekil 3'te verilen grafikte 2018 yilının Ocak-Aralık periyodunda Nahçıvan AAT'nin giriş ve çıkışından alınan 2 saatlik kompozit numunelerin KOİ konsantrasyonlarının değişimi ve deşarj standardı olarak kabul edilen Avrupa Birliği Kentsel Atıksu Arıtımı Direktifinde belirtilen KOİ deşarj limiti gösterilmektedir. Çıkış atıksuyuna ait KOİ konsantrasyonlarının 12 ay süresince yönetmelik deşarj sınırı $125 \mathrm{mg} / \mathrm{L}$ 'den düşük olduğu görülmektedir. En fazla kirlilik konsantrasyonunun olduğu ay Mart 2018'de 305.62 mg/L, en düşük olduğu ay ise Temmuz 2018'de $158.2 \mathrm{mg} / \mathrm{L}$ olarak ölçülmüştür. Analiz süresince ortalama giriş KOİ konsantrasyonu $223.07 \mathrm{mg} / \mathrm{L}$, çıkış konsantrasyonu 18.33 $\mathrm{mg} / \mathrm{L}$ 'dir. Sonuçların kabul edilen yönetmelikte belirlenen KOİ deşarj limitlerine uygun olduğu görülmektedir. Toplam giriş atıksuyuna ait KOİ konsantrasyonlarına bakıldığında, 12 ay süresince tesise gelen ortalama KOİ konsantrasyonu, 
tesisin projelendirme hesaplarında 1. kademe KOİ kirlilik konsantrasyonu olan $335.02 \mathrm{mg} / \mathrm{L}$ 'ye kıyasla yaklaşık \%33 daha düşük olduğu gözlemlenmiştir. Aynı grafikte KOİ giderim verimlerindeki değişim ve proje aşamasında hedeflenen verim de gösterilmektedir.

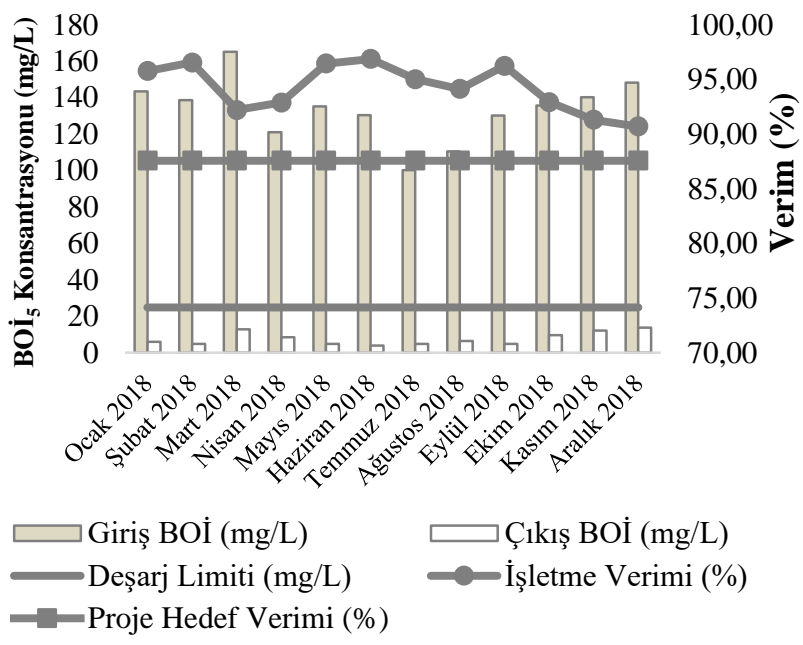

Şekil 2. AAT giriş ve çıkıș atıksu BOİ konsantrasyonları ve $\mathrm{BOI}_{5}$ giderim verimi

Proje aşamasında 1. kademe için KOİ giderim verimi hedefi \% 62.69'dur. Arıtma verimleri analiz edildiğinde KOİ arıtma veriminin yıl boyunca yönetmelikte kabul edilen sınır değerlerin üstünde olduğu görülmektedir. Yıllık ortalama KOİ arıtma verimi \% 92.01 olarak hesaplanmıştır ve proje aşamasında hedeflenen 1 . kademe arıtma veriminin üzerinde olduğu gözlemlenmektedir.
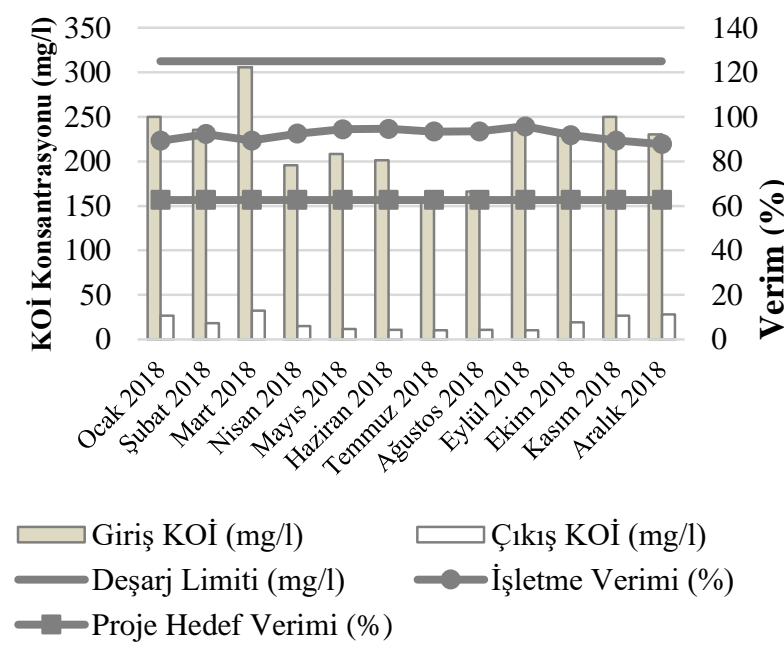

Şekil 3. AAT giriş ve çıkış atıksu KOİ konsantrasyonları ve KOİ giderim verimi

Şekil 4'te verilen grafikte 2018 yılının Ocak-Aralık periyodunda Nahçıvan AAT'nin giriş ve çıkışından alınan 2 saatlik kompozit numunelerin AKM konsantrasyonlarının değişimi ve deşarj standardı olarak kabul edilen Avrupa Birliği Kentsel Atıksu Arıtımı Direktifinde belirtilen AKM deşarj limiti gösterilmektedir. Çıkış atıksuyuna ait AKM konsantrasyonlarının 12 ay süresince yönetmelik deşarj sınırı $35 \mathrm{mg} / \mathrm{L}$ 'den düşük olduğu görülmektedir. En fazla kirlilik konsantrasyonunun olduğu ay Mart 2018'de 152.3 $\mathrm{mg} / \mathrm{L}$, en düşük olduğu ay ise Haziran 2018 'de $80.2 \mathrm{mg} / \mathrm{L}$ olarak ölçülmüştür. Analiz süresince ortalama giriş AKM konsantrasyonu $115.87 \mathrm{mg} / \mathrm{L}$, çıkış konsantrasyonu 3.27 mg/L'dir. Sonuçların kabul edilen yönetmelikte belirlenen AKM deşarj limitlerine uygun olduğu görülmektedir. Toplam giriş AKM konsantrasyonlarına bakıldığında, 12 ay süresince tesise gelen ortalama AKM konsantrasyonu, tesisin projelendirme hesaplarında 1. kademe AKM kirlilik konsantrasyonu olan $234.52 \mathrm{mg} / \mathrm{L}$ 'ye kıyasla yaklaşık \%51 daha düşük olduğu gözlemlenmiştir. Aynı grafikte AKM giderim verimindeki değişim ve proje aşamasında hedeflenen verim de gösterilmektedir.

Proje aşamasında 1. kademe için AKM giderim verimi hedefi \% 85.08'dir. Arıtma verimleri analiz edildiğinde AKM arıtma veriminin y1l boyunca yönetmelikte kabul edilen sınır değerlerin üstünde olduğu görülmektedir. Yıllık ortalama AKM arıtma verimi de \% 97.11 olarak hesaplanmıştır ve proje aşamasında hedeflenen 1. kademe arıtma veriminin üzerinde olduğu gözlemlenmektedir.
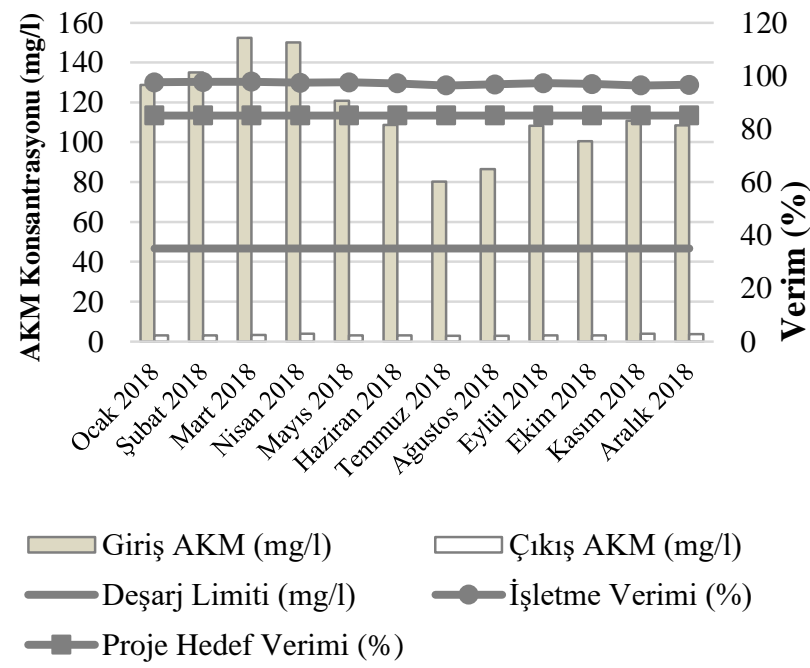

\subsection{Toplam azot ve toplam fosfor giderimi}

Şekil 5'te verilen grafikte 2018 yılının Ocak-Aralık periyodunda Nahçıvan AAT'nin giriş ve çıkışından alınan 2 saatlik kompozit numunelerin TN konsantrasyonlarının değişimi ve deşarj standardı olarak kabul edilen Avrupa Birliği Kentsel Atıksu Arıtımı Direktifinde belirtilen TN deşarj limiti gösterilmektedir. Çıkış numunesinin $\mathrm{TN}$ konsantrasyonlarının 12 ay süresince yönetmelik deşarj sınırı $15 \mathrm{mg} / \mathrm{L}$ 'den düşük olduğu görülmektedir. En fazla kirlilik konsantrasyonunun olduğu ay Mart 2018'de 25.6 $\mathrm{mg} / \mathrm{L}$, en düşük olduğu ay ise Temmuz 2018'de $15.7 \mathrm{mg} / \mathrm{L}$ olarak ölçülmüştür. Analiz süresince ortalama giriş TN konsantrasyonu $20.10 \mathrm{mg} / \mathrm{L}$, çıkış konsantrasyonu 4.98 mg/L'dir. Sonuçların kabul edilen yönetmelikte belirlenen TN deşarj limitlerine uygun olduğu görülmektedir. Toplam giriş TN konsantrasyonlarına bakıldığında, 12 ay süresince tesise gelen ortalama TN konsantrasyonu, tesisin projelendirme hesaplarında 1. kademe TN kirlilik 
konsantrasyonu olan $33.50 \mathrm{mg} / \mathrm{L}$ 'ye kıyasla yaklaşık \%40 daha düşük olduğu gözlemlenmiştir. Aynı grafikte TN giderim verimindeki değişim ve proje aşamasında hedeflenen verim de gösterilmektedir.

Proje aşamasında 1. kademe için TN giderim verimi hedefi \%55.22'dir. Arıtma verimleri analiz edildiğinde TN arıtma veriminin yıl boyunca yönetmelikte kabul edilen sınır değerlerin üstünde olduğu görülmektedir. Y1llık ortalama TN arıtma verimi de \%75.98 olarak hesaplanmıştır ve proje aşamasında hedeflenen 1. kademe arıtma veriminin üzerinde olduğu gözlemlenmektedir.

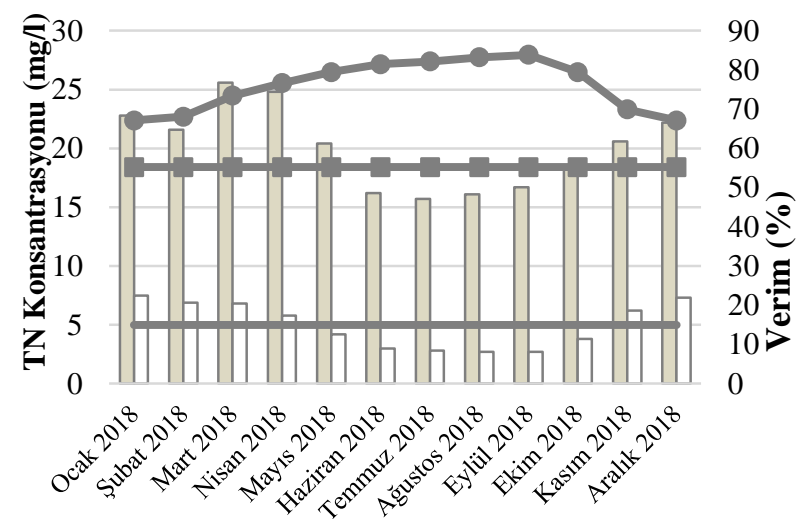

$$
\begin{aligned}
& \square \text { Giriş TN (mg/l) } \quad \square \text { Çıkış TN (mg/l) } \\
& \square \text { Deşarj Limiti (mg/l) } \quad \text { İşletme Verimi (\%) } \\
& \square \text { Proje Hedef Verimi (\%) }
\end{aligned}
$$

Şekil 5. AAT giriş ve çıkış atıksu TN konsantrasyonları ve TN giderim verimi

TN arıtma veriminin kış aylarında düştüğü gözlenmiştir. Düşük sıcaklıklarda denitrifikasyon bakterilerinin çalışma hızları da büyük oranda düşer. Yapılan literatür araştırmalarına göre denitrifikasyon için gereken bekletme süresi suyun sıcaklığına bağlıdır ve denitrifikasyon işleminin süresini artırmaktadır [9]. Özellikle ortalama sıcaklığın $0^{\circ} \mathrm{C}$ 'nin altına düştüğü Aralık ve Ocak aylarında TN arıtma veriminde düşüş gözlenmesinin sebebi iklimsel veriler ile ilişkilendirilebilir. Azot giderim mekanizmasında özellikle soğuk havalarda yüksek çamur yaşı gerekmektedir. Tesiste yüksek çamur yaşı ile çalışılması ise anaerobik havuza nitrat girdisine sebep olarak TP giderim verimini düşürmektedir. Ayrıca giriş kirlilik yükleri hesaplanan 1. kademe kirlilik yüklerinden düşük olduğundan, denitrifikasyon havuzunda denitrifikasyonun gerçekleşmesi için yeterli karbon kaynağının bulunmaması da TN giderim verimini etkilemektedir.

Şekil 6'da verilen grafikte 2018 yılının Ocak-Aralık periyodunda Nahçıvan AAT'nin giriş ve çıkışından alınan 2 saatlik kompozit numunelerin TP konsantrasyonlarının değişimi ve deşarj standardı olarak kabul edilen Avrupa Birliği Kentsel Atıksu Arıtımı Direktifinde belirtilen TP deşarj limiti gösterilmektedir. Buna göre çıkış numunesinin TP konsantrasyonlarının 12 ay süresince yönetmelik deşarj sınırı $2 \mathrm{mg} / \mathrm{L}$ 'den düşük olduğu görülmektedir. Analiz süresince ortalama giriş TP konsantrasyonu 5.46 mg/L, çıkış konsantrasyonu $0.79 \mathrm{mg} / \mathrm{L}$ 'dir. Sonuçların kabul edilen yönetmelikte belirlenen TP deşarj limitlerine uygun olduğu görülmektedir. Toplam giriş TP konsantrasyonlarına bakıldığında, 12 ay süresince tesise gelen ortalama TP konsantrasyonu, tesisin projelendirme hesaplarında 1 . kademe TP kirlilik konsantrasyonu olan 10.05 mg/L'ye kıyasla yaklaşık \%45 daha düşük olduğu gözlemlenmiştir. Aynı grafikte TP giderim verimindeki değişim ve proje aşamasında hedeflenen verim de gösterilmektedir.

Proje aşamasında 1. kademe için TP giderim verimi hedefi $\% 80.10$ olarak belirlenmiştir. Yıllık ortalama TP arıtma verimi \%85.20 olarak bulunmuştur ve proje aşamasında hedeflenen 1. kademe arıtma veriminin üzerinde olduğu gözlemlenmektedir.
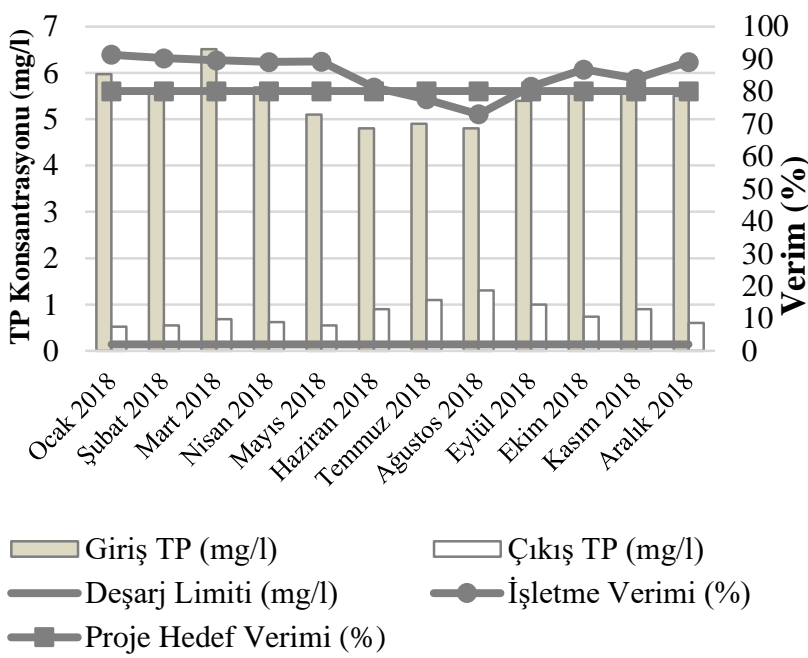

Şekil 6. AAT giriş ve çıkış atıksu TP konsantrasyonları ve TP giderim verimi

Grafikte görüldüğü üzere giriş TP konsantrasyonları hesaplanan 1. kademe kirlilik konsantrasyonuna göre düşük olmasına rağmen temmuz ve ağustos aylarında tesis TP arıtımında hedeflenen arıtma verimini sağlayamamıştır. Giriş suyundaki besi maddelerinin düşük konsantrasyonda bulunması, bekletme sürelerinin uzun olduğu havalandırmalı aktif çamur sistemlerinde içsel solunum hızını artırmaktadır. Ortamdaki besin maddelerini tüketen bakteriler birbirlerini tüketmeye başlamakta ve bu şekilde de oksijen tüketimi artmaktadır. Azalan oksijen ve sıcak iklim şartları bakterilerin bünyelerindeki fosforu suya salmalarına sebebiyet vermektedir.

$\mathrm{A}^{2} \mathrm{O}$ proseslerinde fosfor gideriminin yanı sıra azot giderim mekanizması da eş zamanlı olarak çalışır. Eşzamanlı nitrtifikasyon-denitrifikasyon prosesinin azot giderimi \%80 ile sınırlı olduğundan azotun tamamı giderilmez. Anaerobik havuza nitrat gelmesi sonucu nitrata bağlı $\mathrm{O}_{2}$ anaerobik şartları bozar ve sistemin $\mathrm{P}$ giderim verimi düşer. $\mathrm{Bu}$ duruma önlem olarak $\mathrm{A}_{2} \mathrm{O}$, Bardenpho prosesi gibi eş zamanlı nitrifikasyon-denitrifikasyon ve fosfor giderim mekanizmalarında projelendirme aşamasında anoksik havuz tek olarak teşkil edilmemeli, birden fazla anoksik havuz teşkil edilmelidir. Geri devir edilen çamur anoksik 
tanklardan birine verilerek burada çamurdaki nitrattan arındırılarak anaerobik havuza verilmelidir.

\subsection{F/M oranı, geri devir oranı, çamur yaşı ve diğer parametreler}

Nahçıvan AAT projelendirilirken $\mathrm{F} / \mathrm{M}=0.3$, MLVSS $=3000 \mathrm{mg} / \mathrm{L}$ ve geri devir oran $1 \mathrm{R}=0.7$ olarak kabul edilmiştir. MLVSS, F/M, MLSS, çamur yaşı, geri devir oranı hesaplanırken literatürdeki standart metotlar kullanılmıștır. Proje kirlilik yükünün gereğinden yüksek seçilmesi ve nüfus verileri ile mevcut nüfusun yerleşik yaşamaması dolayısıyla tesise düşük debi girişinin olması projelendirme aşamasındaki $\mathrm{F} / \mathrm{M}$ oranının, MLVSS konsantrasyonunun düşmesine sebep olmus ve çeşitli işletme sorunları ortaya çıkmıştır. Tesis için MLSS/MLVSS $>0.85$ olduğundan F/M hesaplarında MLSS kullanılmış olup gerekli F/M oranını sağlamak için geri devir oranı $\mathrm{R}=0.9$ olarak düzenlemeler yapılmıștır. Geri devirin artırılması ile çamur yaşı ayarlaması yapılarak MLSS konsantrasyonu ve F/M oranı istenilen seviyelere ulaşmış olup hem filamentli mikroorganizma sorunu çözülmüş hem de denitrifikasyonun artırılması amaçlanmıştır. Sistemin çamur yaşı proje aşamasında 23 gün olarak belirlenmiş olup, belirlenen çamur yaşı değerinde işletilmektedir. Tesisteki havuzların oksidasyon redüksiyon potansiyeli (ORP) ise anaerobik havuz ORP $=-150 \mathrm{mV}$, anoksik havuz $\mathrm{ORP}=-45 \mathrm{mV}$, aerobik havuz $\mathrm{ORP}=+80 \mathrm{mV}$ olarak belirlenmiştir ve bu değerlere yakın değerlerde tesis işletilmektedir. Tesis giriş atıksuyunun $\mathrm{pH}$ değeri 6.5-7 arasında değişmekte olup, tesis çıkışında $\mathrm{pH}$ değeri 7-7.5 aralığında olmaktadır.

\section{Sonuçlar}

Bu çalışmada Nahçıvan AAT'nin 12 aylık işletme verimi analizi yapılarak, proje aşamasında hedeflenen verim ile karşılaştırılması yapılmıştır. Organik madde bazında atıksu karakterizasyonu zayıf atıksu olarak değerlendirilmiştir.

Tesise ulaşan atıksuyun debisi ve kirlilik yükü, projede öngörülen debiden ve kirlilik yükünden yüksek oranda düşüktür. Ortalama $\mathrm{BOI}_{5}, \mathrm{KOI}, \mathrm{AKM}, \mathrm{TN}$ ve TP konsantrasyonları değerlendirildiğinde, 1. kademe proje kirlilik konsantrasyonlarına kıyasla BOİ $_{5}$ ve KOİ konsantrasyonunun yaklaş1k \%33, AKM konsantrasyonunun $\% 51$, TN konsantrasyonunun \%40 ve TP konsantrasyonunun yaklaşık \%45 düşük olduğu gözlemlenmiștir. Ortalama giderim verimlerine bakıldığında $\mathrm{BOI}_{5}, \mathrm{KOI}, \mathrm{AKM}, \mathrm{TN}$ giderim verimleri hedeflenen verimleri sağlamakta, TP giderim verimi ise bazı aylarda hedeflenen verimi sağlamamaktadır. Kirlilik yüklerinin yüksek hesaplanması sonucu C:N:P oranı değişmekte ve karbon kaynağ eksikliğinden kaynaklı çeşitli işletme problemleri ve verim kaybı oluşmaktadır. Bunun yanı sıra tesisin yüksek kirlilik konsantrasyonuna göre tasarlanması sonucu denitrifikasyon aşamasında karbon kaynağı yetersiz kalmakta ve ilave karbon kaynağı ek maliyet olarak geri dönmektedir.

Değirmenci vd. [6] tarafından yapılan çalışmada tesis hesaplamaları yapilırken yerinde atıksu analizi yapılmamasının ve gereğinden fazla birakılan emniyet paylarının tesisin ilk yatırım ve işletme maliyetlerini artırdığ belirtilmiştir. Tesis tasarımı aşamasında yapılan bu hata tesisin boyutlarının ve makine teçhizatının gerekenden daha büyük kapasitelerde seçilmesine dolayısıyla olumsuz ekonomik sonuçlara sebep olmuştur.

Atıksu arıtma tesisleri projelendirilirken, hesaplamalar mevcut nüfus üzerinden gelecek nüfusun tahmini yapılarak sürdürülmekte ve bu verilere bağlı olarak tasarımın ilk adımı olan kirlilik yükleri, debi hesabı yapılmaktadır. Yatırım maliyeti oldukça yüksek olan bu tesisler hayata geçirilmeden önce, proje bölgesindeki ortama debinin ve kirlilik yükünün varsa mevcut kanalizasyondan ölçülmesi ve proje hesaplarının bu veriler de göz önüne alınarak yapılması gerekmektedir. Ayrıca seçilen prosesin oluşturabileceği işletme sorunları araştırılmalı varsa mevcut uygulamalarda yapılan modifikasyonlar göz önüne alınarak tasarımlar yapılmalıdır. Yerinde ölçümler analiz edilerek proje tasarım verileri ile yüksek bir farklılık durumunda yapım işleri ihalesi yapılmamalıdır. Farklılığın sebebi araștırılarak nüfusa kıyasla rasyonel veriler elde edildikten sonra arıtma tesisi yapımı işleme konulmalı ve mühendisliğin gereklerinden birisi olan ekonomik bir tasarım yapılmalıdır.

\section{Teşekkür}

İnceleme ve araştırma yapmak için ihtiyacımız olan bilgi ve verileri bizimle paylaşarak bu çalışmanın gerçekleştirilmesinde büyük katkı sağlayan Naxçıvan Muxtar Respublikası Dövlət Meliorasiya və Su Təsərrüfatı Komitəsi'ne teşekkür ederiz.

\section{Çıkar çatışması}

Yazarlar çıkar çatışması olmadığını beyan etmektedir.

Benzerlik oranı (iThenticate): $\% 6$

\section{Kaynaklar}

[1] H. Yayli, Çevre etiği bağlamında kalkınma, çevre ve nüfus. Süleyman Demirel Üniversitesi Sos. Bilim. Enstitüsü Dergisi, 15 (1), 151-169, 2012.

[2] M. Tanyol ve G. Uslu, Tunceli evsel atıksu arıtma tesisinin arıtma etkinliğinin değerlendirilmesi. Mehmet Akif Ersoy Üniversitesi Fen Bilimleri Enstitüsü Dergisi, 4 (1), 24-29, 2013.

[3] U.S.E.P.A, Design Manual: Onsite Wastewater Treatment and Disposal Systems. U.S. Environmental Protection Agency (USEPA), Washington DC, 1980.

[4] T. D. Reynolds and P. A. Richards, Unit Operations and Processes in Environmental Engineering. PWS Publishing Company, Boston, 1996.

[5] S. R. Qasim, Wastewater Treatment Plants: Planning, Design, and Operation, Second Edition. CRC Press, Florida, 1998

[6] M. Değirmenci, A. Altın, ve S. Altın, Atıksu miktarı ve BOİ 5 kirlilik yükünün, havalandırma havuzu ilk yatırım ve enerji maliyetlerine olan etkilerinin incelenmesi. Dokuz Eylül Üniversitesi Mühendislik Fakültesi Fen ve Mühendislik Dergisi, 2(1), 1-12, İzmir, 2000.

[7] I. Metcalf \& Eddy, G. Tchobanoglous, F. Burton, and H. D. Stensel, Wastewater Engineering: Treatment and Reuse. McGraw-Hill Education, New York, 2002.

[8] N. Alpaslan ve D. Dölgen, Atıksu Arıtma Tesislerinin Tasarım Ve Proje Kontrol Esasları. TMMOB Çevre Mühendisleri Odası, İzmir, 2004. 
[9] M. Topal ve E. I. Topal, 2010-2011 Kış sezonunda Elazı ğ belediyesi atıksu arıtma tesisinin bazı parametrelerle değerlendirilmesi. Cumhuriyet Üniver sitesi Fen Edebiyat Fakültesi Fen Bilimleri Dergisi, 32 (1), 1-12, 2012.
[10] Ş. Tatar ve M. Sağlam, Kızıltepe ileri biyolojik atıksu arıtma tesisinin $\mathrm{KOI}, \mathrm{BOİ}_{5}$ ve $\mathrm{AKM}$ yönünden işletme verimliliğinin değerlendirilmesi. Avrupa Bilim ve Teknol. Dergisi, 20 (1), 265-269, 2020, http:// doi:10.31590/ejosat.770260. 